\title{
Analisis Struktur Dermaga Pupuk NPK di Tersus PT. Pupuk Kalimantan Timur untuk Kapal BULK Carrier dengan Kapasitas 10.000 DWT
}

\author{
Cahya Buana ${ }^{1}$, Fuddoly ${ }^{1}$, M. Dwi Nugroho ${ }^{1}$, Kurnia Hadi Putra ${ }^{2}$, \\ Nafilah El Hafizah ${ }^{2}$ dan Ratih Sekartadji ${ }^{2}$ \\ ${ }^{1}$ Departemen Teknik Sipil, FTSPK, Institut Teknologi Sepuluh Nopember Surabaya \\ ${ }^{2}$ Departemen Teknik Sipil, FTSP, Institut Teknologi Adhi Tama Surabaya \\ E-mail : cahya2772@gmail.com, kurnia_putra@itats.ac.id
}

\begin{abstract}
The planned development of facilities at PT. Pupuk Kaltim is to build a special pier for NPK fertilizer. This development is expected to help the NPK fertilizer distribution process effectively, efficiently, and quickly. The planned is a quadrant shiploader type dock for 10,000 DWT vessel capacity. This pier planning has been realized in the form of a pier development plan. However, to realize this development, detailed engineering design is needed which includes fender and boulder systems, trestle planning, pivot, loading platforms, mooring dolphin, breasting dolphin, catwalk, piling, and reinforcement details. In addition to the detailed engineering design, it is also necessary to review the depth of the water in the PT. East Kalimantan Pupuk. Concrete work in this final project is planned to use conventional concrete or in situ concrete, but in the method of implementation, the contractor can try to use a precast system but still refers to the design that has been planned in this final project. Pier planning does not only include planning sea facilities as well as pier structure planning. In addition, it is also necessary to plan related to the method of implementing the construction of funds in the pier planning. Results analysis obtained the need for the pier with trestle dimensions of $4 \times 50 \mathrm{~m} 2$, pivot $8 \times 14 \mathrm{~m} 2$, loading platform $3 \times 82 \mathrm{~m} 2$, mooring dolphin $3.8 \times 3.8 \mathrm{~m} 2$, breasting dolphin at $4.8 \times 4.8 \mathrm{~m} 2$.
\end{abstract}

Keywords: Trestle, Pivot, Loading Platform, Mooring Dolphin, Breasting Dolphin, Catwalk

\begin{abstract}
Abstrak
Adanya rencana pengembangan fasilitas di tersus PT. Pupuk Kaltim yaitu dengan membangun dermaga khusus pupuk NPK. Pengembangan ini diharapkan dapat membantu proses distribusi pupuk NPK dengan efektif, efisien, dan cepat. Dermaga yang direncanakan adalah dermaga jenis quadrant shiploader untuk kapasitas kapal 10.000 DWT. Perencanaan dermaga ini telah diwujudkan dalam bentuk rencana pengembangan dermaga. Namun untuk mewujudkan pembangunan tersebut diperlukan detail engineering desain yang meliputi sistem fender dan boulder, perencanaan trestle, pivot, loading platform, mooring dolphin, breasting dolphin, catwalk, pemancangan, dan detail penulangan. Selain detail engineering desain, perlu ditinjau juga terhadap kedalaman air pada alur masuk tersus PT. Pupuk Kaltim. Untuk pengerjaan pembetonan pada tugas akhir ini direncanakan menggunakan beton konvensional atau cor in situ, namun dalam metode pelaksanaannya, pihak kontraktor dapat mengupayakan menggunakan sistem pracetak namun tetap mengacu pada desain yang telah direncanakan pada tugas akhir ini. Perencanaan dermaga tidak hanya mencakup perencanaan fasilitas laut serta perencanaan struktur dermaga saja. Selain itu perlu juga direncanakan terkait metode pelaksanaan pembangunan dana dalam perencanaan dermaga juga harus ditinjau terkait rencana anggaran biaya dari dermaga tersebut. Dari hasil analisis perhitungan didapatkan kebutuhan dermaga dengan dimensi trestle sebesar $4 \times 50 \mathrm{~m} 2$, pivot $8 \times 14 \mathrm{~m} 2$, loading platform $3 \times$ $82 \mathrm{~m} 2$, mooring dolphin $3,8 \times 3,8 \mathrm{~m} 2$, breasting dolphin sebesar 4,8 x 4,8 m2.
\end{abstract}

Kata kunci : Trestle, Pivot, Loading Platform, Mooring Dolphin, Breasting Dolphin, Catwalk 


\section{Pendahuluan}

PT. Pupuk Kaltim saat ini meningkatkan proses produksi dan distribusi. Peningkatan ini belum didukung oleh keberadaan fasilitas bongkar terutama untuk sarana khusus loading bahan baku pupuk NPK, sehingga diperlukan pembangunan dermaga NPK pada tersus PT. Pupuk Kaltim. Dalam penggunaannya, dermaga NPK diharapkan akan membantu proses loading pupuk jenis NPK di tersus PT. Pupuk Kaltim dalam skala yang besar [1].

Dalam perencanaan dermaga untuk loading pupuk NPK perlu dipertimbangkan berdasarkan karakteristik dari bahan pupuk (Phospate). Phospate adalah bahan baku utama industri pupuk. Sangat berdebu dan menyerap kelembapan dengan sangat cepat yang berarti sangat pekat dengan air. Faktor penyimpanan rata-rata adalah sebesar $0,92 \mathrm{~m}^{3}$ sampai $1 \mathrm{~m}^{3}$ per metrik ton dan semua pengiriman dalam bentuk konsentrat bubuk (Velsink, 1994). Dengan karaktersitik pupuk tersebut, diperlukan suatu perencanaan sistem loading yang bisa menghindari air, lebih cepat dan mempermudah pekerjaan. Sehingga perlu menggunakan alat bantu loading bahan baku pupuk yaitu ship loader dan belt conveyor untuk dermaga NPK [7].

Lokasi perencanaan dermaga NPK di tersus PT. Pupuk Kaltim untuk kapal bulk carrier kapasitas 10.000 DWT ini adalah di Bontang, Provinsi Kalimantan Timur. Lokasi perencanaan secara terperinci ditunjukkan oleh Gambar 1. .Lokasi pengembangan berada pada koordinat Garis Lintang $0^{\circ} 10^{\prime} 18.87^{\prime \prime} \mathrm{U}$ dan Garis Bujur 117²9'16.29"T.

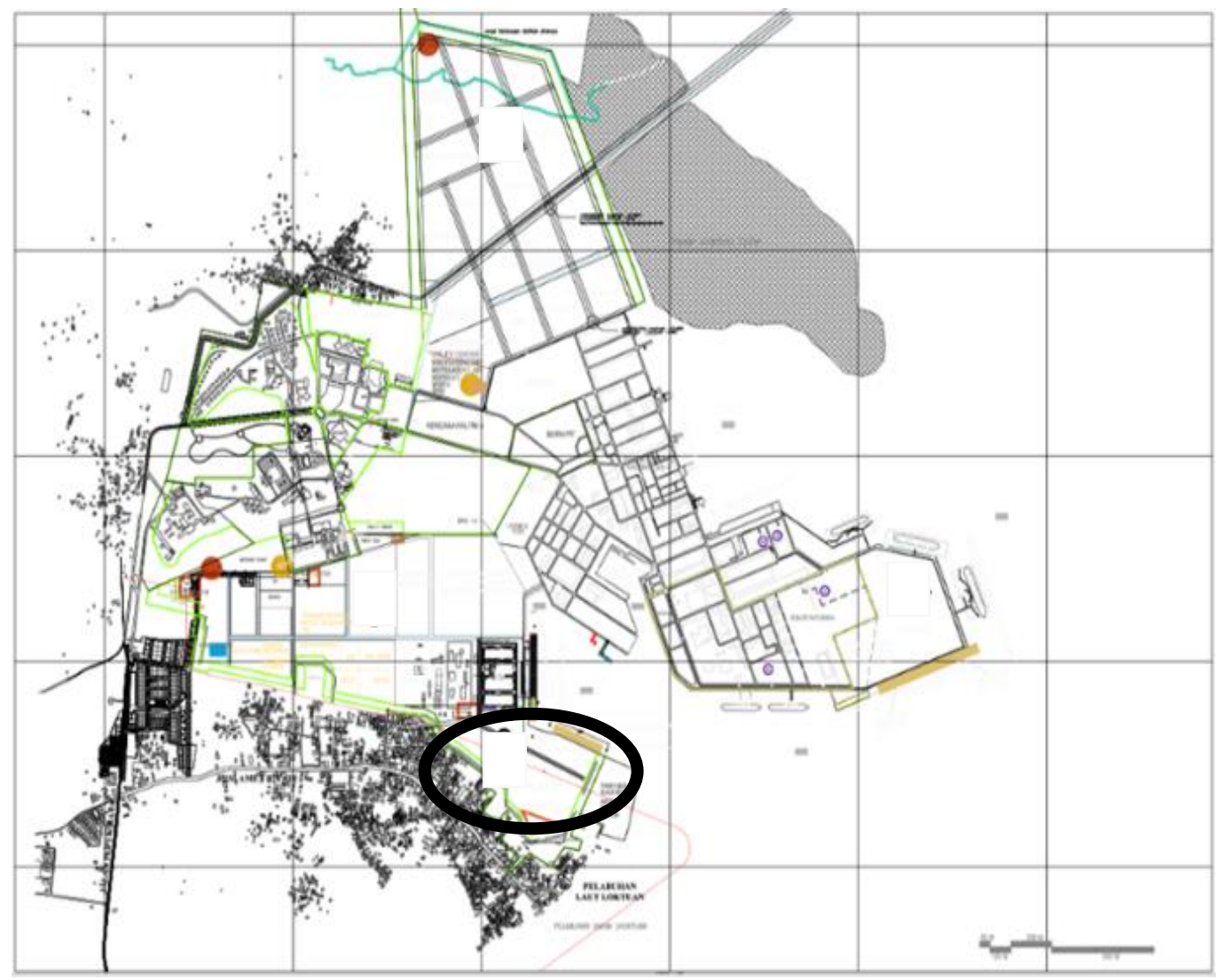

Gambar 1. Lokasi Perencanaan Dermaga NPK

\section{Metode}

Diagram alir proses analisa struktur dermaga adalah seperti tampak pada Gambar 2. Dengan memperhatikan urutan pelaksanaan yang dimulai dari tinjauan Pustaka yang selanjutnya diikuti oleh pengumpulan data. 


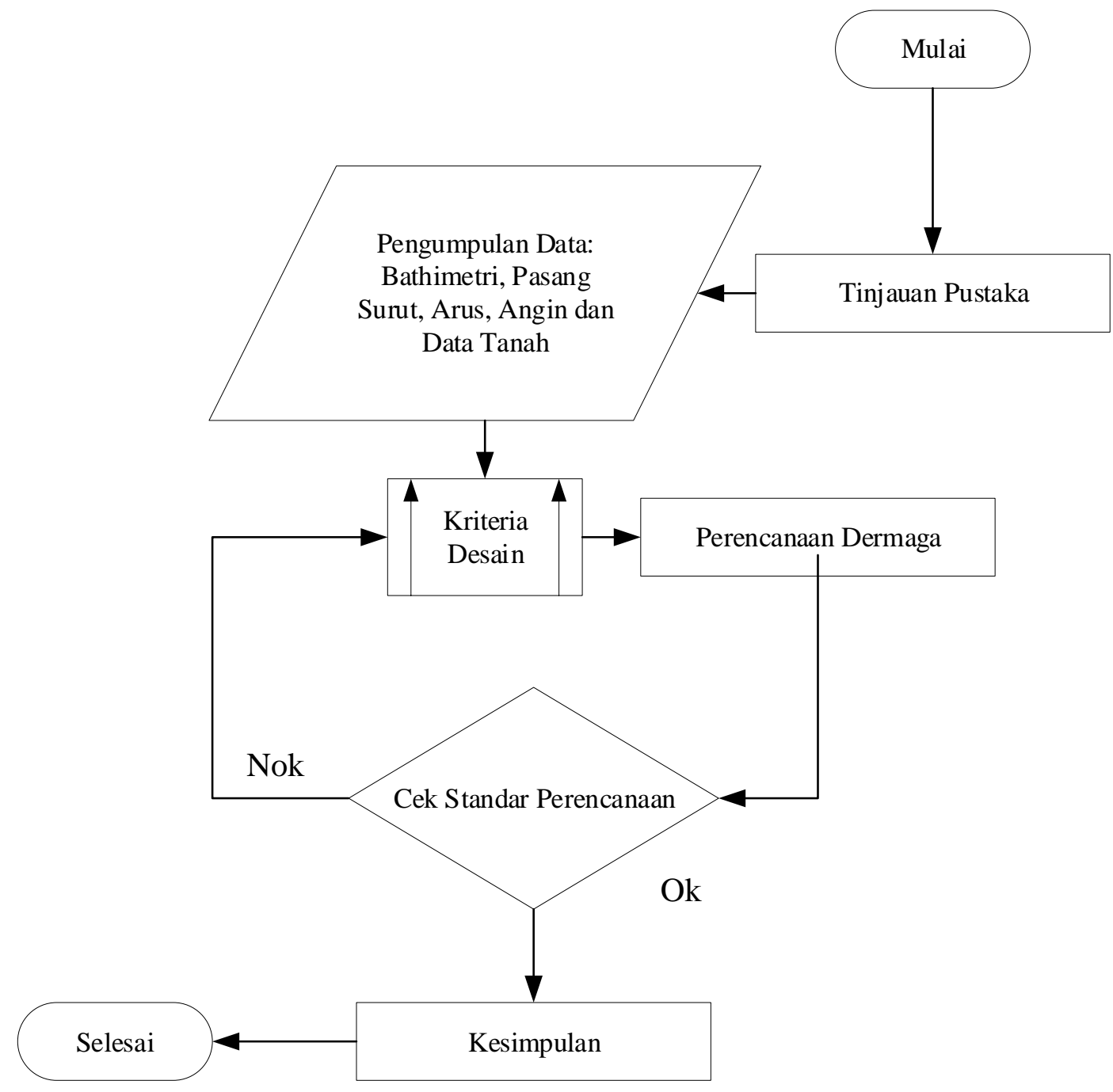

Gambar 2. Flowcart Proses Perencanaan Struktur Dermaga

\section{Hasil dan Pembahasan}

\section{(1) Kriteria Desain}

Berdasarkan PIANC (2014). Diperoleh spesifikasi kapal bulk carrier sebagai berikut :

$\begin{array}{ll}\text { Type of vessel } & : \text { Used Bulk Carrier } \\ \text { GRT/NRT } & : 6079 / 3290 \\ \text { DWT } & : 10000 \mathrm{MT} \\ \text { Length } & : 130 \mathrm{~m} \\ \text { Breadth } & : 18 \mathrm{~m} \\ \text { Depth } & : 10,3 \mathrm{~m} \\ \text { Draft } & : 7.5 \mathrm{~m}\end{array}$

Fasilitas Belt Conveyor digunakan untuk mengangkut pupuk NPK dari darat menuju ke shiploader (Gambar 4.2). Belt Conveyor yang digunakan adalah tipe Itaguai-RJ K7014 PC 100 kapasitas 5000 ton/jam dan berat $700 \mathrm{~kg} / \mathrm{m}$.

Fasilitas shiploader digunakan untuk loading Pupuk NPK dari belt conveyor ke kapal bulk carrier. Shiploader ini memiliki lengan teleskopik (dapat memanjang dan memendek) dan memiliki rel 
berbentuk radial (setangah lingkaran). Shiploder yang digunakan adalah tipe PL 400-2000/41,5+41, kapasitas 5000 ton/jam dan berat 120 ton.

\section{(2) Perencanaan Fender dan Bollard}

Dengan $\mathrm{E}_{\mathrm{AB}}=17,29 \mathrm{tm}$, maka direncanakan untuk menggunakan sistem fender tunggal dari ANP Arch Fender 800 E 1.0 dengan data-data sebagai berikut:

$$
\begin{aligned}
& \text { - Energi } \quad=18,05 \text { ton.m } \quad(>17,29 \text { ton.m }) \\
& \text { - Reaksi } \quad=53,69 \text { ton } \\
& \text { - Berat fender } \quad=871 \mathrm{~kg}
\end{aligned}
$$

Dari spesifikasi kapal didapat gaya tarik maksimal pada bollard adalah 100ton sehingga dipilih tipe Dockside Bollard Type Tee dengan spesifikasi sebagai berikut:

- Kapasitas tarik bollard $\quad=60$ ton

- Jumlah baut $\quad=7$ buah

- Diameter baut $\quad=2,5$ in

\section{(3) Perencanaan Struktur Dermaga}

Langkah pertama dalam merencanakan struktur dermaga adalah merencanakan struktur sekunder yaitu pelat lantai. Komponen struktur yang menggunakan struktur pelat adalah trestle, pivot, dan loading platform. Perencanaan balok dilakukan dengan melakukan preliminary design dan pemodelan struktur pada SAP2000 pada struktur trestle, pivot, dan loading platform yang dapat dilihat pada Gambar 3.
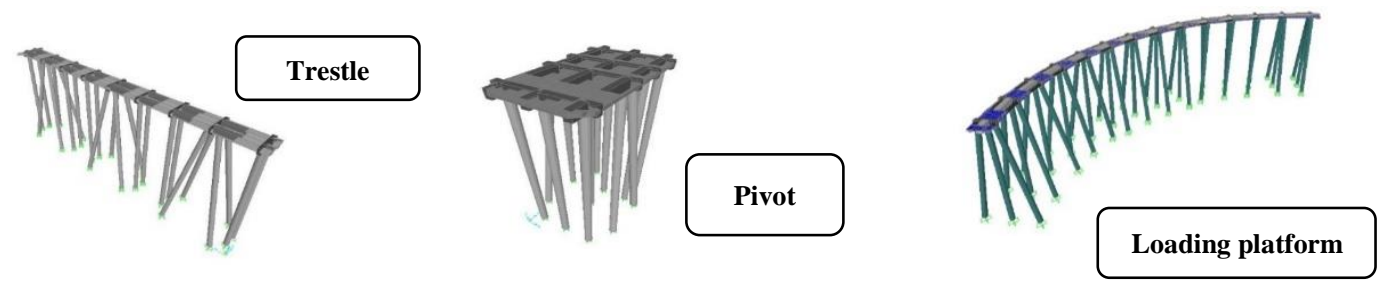

Gambar 3. Pemodelan Struktur

Output hasil running SAP2000 digunakan untuk perhitungan struktur utama seperti balok dan tiang pancang. Untuk perhitungan balok, sama seperti peritungan tulangan lentur pada pelat menggunakan lentur cara "n", namun yang membedakan pada balok menggunakan nilai $\delta=0,4$. Contoh gambar penulangan balok dapat dilihat pada Gambar 4, Gambar 5. Dan Gambar 6.

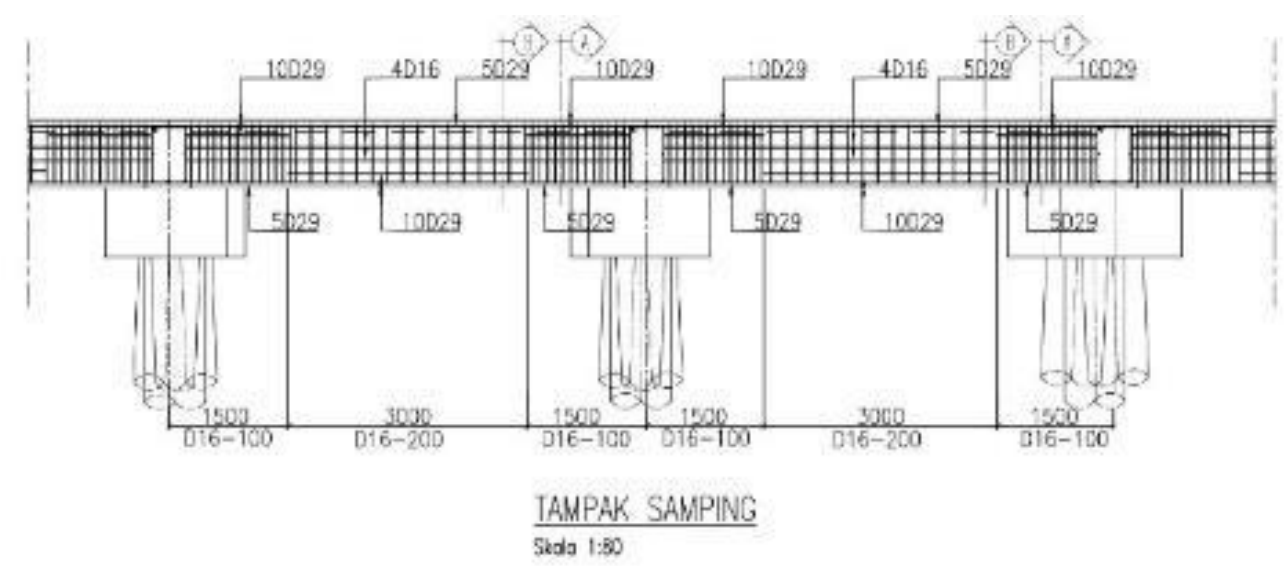

(a) 

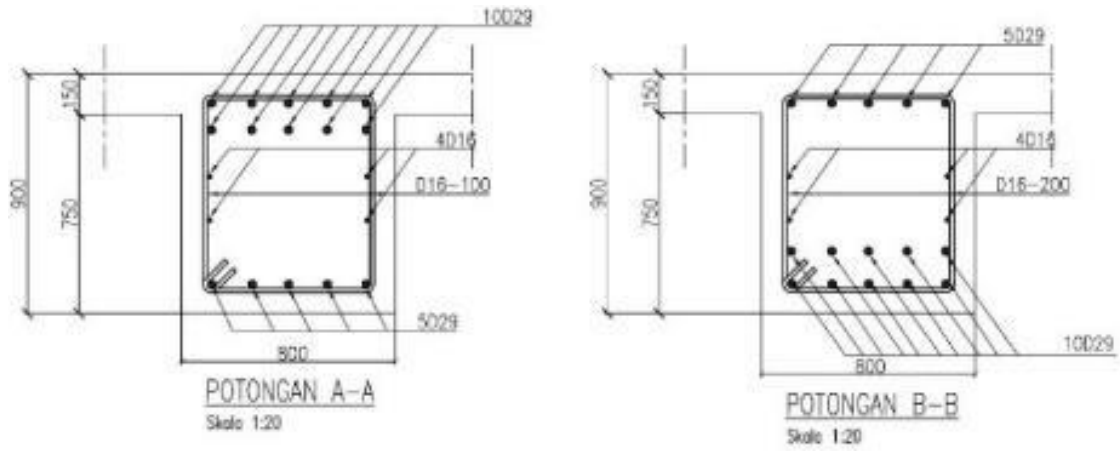

(b)

Gambar 4. Detail Penulangan Balok Loading Platform ; (a) Tampak samping struktur, (b) detail potongan

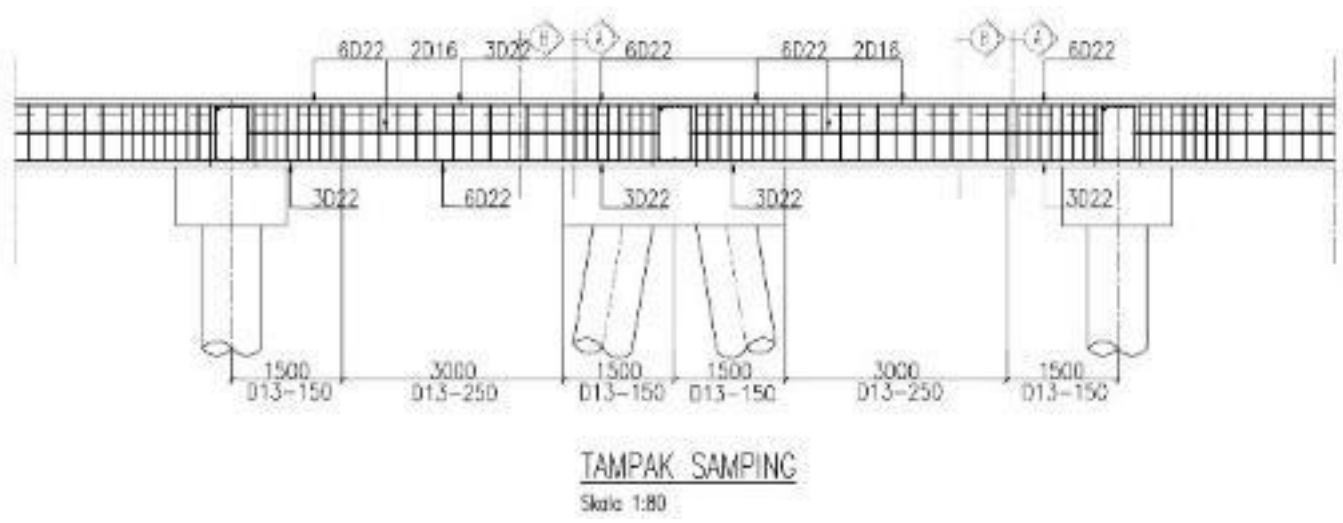

(a)

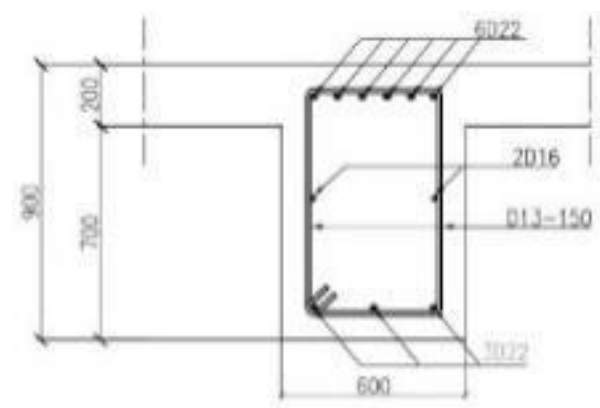

POTONGAN A-A

Sido 1.20

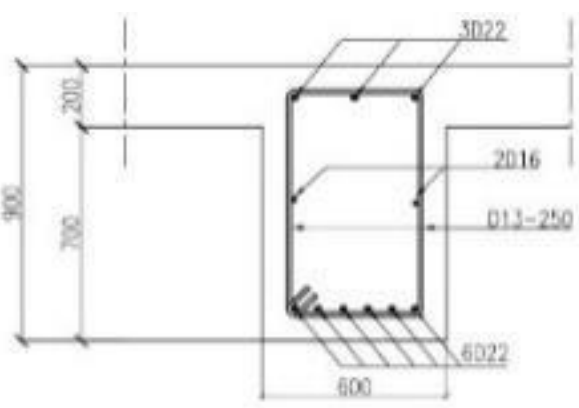

POTONGAN B-B

(b)

Gambar 5. Detail Penulangan Balok Trestle ; (a) Tampak samping struktur, (b) detail potongan

Setelah dilakukan perencanaan struktur trestle, pivot, dan loading platform, selanjutnya direncanakan struktur mooring dolphin dan breasting dolphin. Perencanaan secara prinsip sama seperti pada elemen struktur sebelumnya, namun untuk mooring dolphin dan breasting dolphin hanya terdiri dari poer dan tiang pancang. Untuk menghitung kebutuhan penulangan dilakukan pemodelan struktur yang dapat dilihat pada Gambar 7.

Hasil analisa gaya dalam yang terjadi pada tiang pancang adalah sebagai berikut:

$\mathrm{Qp} \quad=\mathrm{SF} \times \mathrm{P}$ tarik

$=3 \times 78,43$ Ton

$=235,299$ Ton 
Dengan gaya tarik tersebut maka dibutuhkan kedalaman tiang minimum sedalam $24 \mathrm{~m}$ dibawah seabed atau -33 m LWs

$$
\begin{aligned}
\mathrm{Qp} & =\mathrm{SF} \times \mathrm{P} \text { tekan } \\
& =3 \times 108,616 \text { Ton } \\
& =325,848 \text { Ton }
\end{aligned}
$$

Dengan gaya tekan tersebut maka dibutuhkan kedalaman tiang minimum sedalam $27 \mathrm{~m}$ dibawah seabed atau -36 m LWS. Sehingga kedalaman breasting dolphin dapat ditentukan yaitu -36 m LWS.
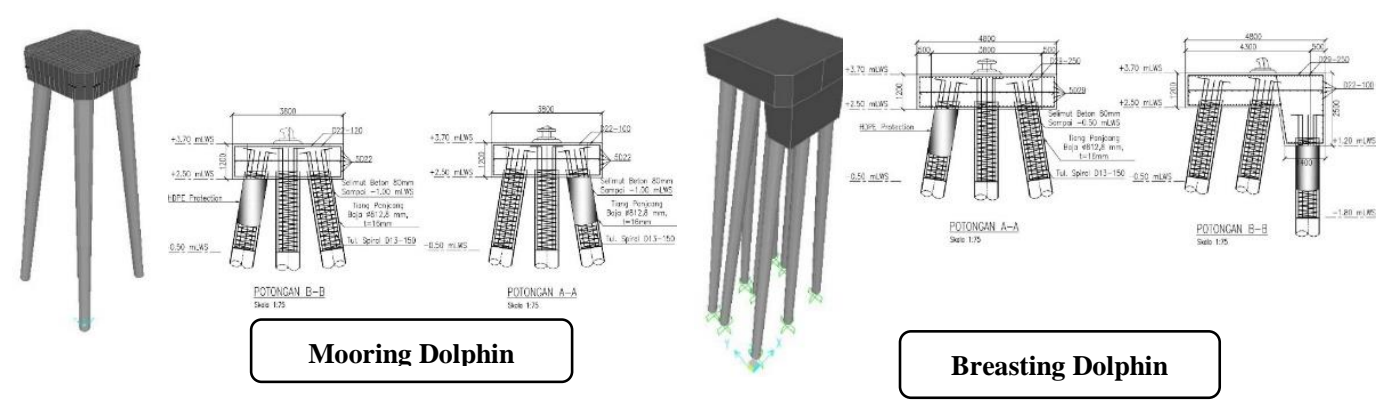

Gambar 7. Mooring dan Breasting Dolphin

\section{Kesimpulan}

Berdasarkan keseluruhan hasil perencanaan diperoleh kesimpulan sebagai berikut :

a. Struktur Trestle direncanakan beton bertulang dengan spesifikasi :

- Dimensi struktur : $4 \times 50 \mathrm{~m}$

- Dimensi balok melintang : $60 \times 90 \mathrm{~cm}$

- Dimensi balok memanjang : 60 x $90 \mathrm{~cm}$

- Tebal Pelat $: 20 \mathrm{~cm}$

b. Struktur Pivot direncanakan beton bertulang dengan spesifikasi :

- Dimensi struktur $\quad: 8 \times 14 \mathrm{~m}$

- Dimensi balok melintang : $60 \times 90 \mathrm{~cm}$

- Dimensi balok memanjang : $60 \times 90 \mathrm{~cm}$

- Tebal Pelat : $30 \mathrm{~cm}$

c. Struktur Loading Platform direncanakan beton bertulang dengan spesifikasi :

- Dimensi struktur $\quad: 3 \times 82 \mathrm{~m}$

- Dimensi balok melintang : $60 \times 90 \mathrm{~cm}$

- Dimensi balok memanjang : $80 \times 90 \mathrm{~cm}$

- Tebal Pelat : $15 \mathrm{~cm}$

d. Struktur Breasting Dolphin direncanakan beton bertulang dengan spesifikasi :
- Dimensi struktur
: $4,8 \times 4,8 \mathrm{~m}$
- Tebal poer
$: 120 \mathrm{~cm}$
- Bollard
: Tee Bollard 60
- Fender
: ANP 100
- Tiang pancang
: Ø812,8 mm
- Kemiringan tiang
$: 6: 1$

e. Struktur Mooring Dolphin direncanakan beton bertulang dengan spesifikasi :

- Dimensi struktur

- Tebal poer

$: 3,8 \times 3,8 \mathrm{~m}$

- Mutu beton

$: 120 \mathrm{~cm}$

: K -350 

- Mutu baja
: U -32
- Boulder
: Tee Bolard 60
- Tiang pancang
: $\varnothing 812,8 \mathrm{~mm}$
- Kemiringan tiang
$: 6: 1$

\section{Referensi}

[1] Website Resmi PT. Pupuk Kalimantan Timur. 2018. Distribusi Pupuk NPK Subsidi dan Non Subsidi, URL:http://pupukkaltim.com

[2] Standar Nasional Indonesia. 2012.SNI-03-1726-2012-Standar Perencanaan Ketahanan Gempa Untuk Struktur Bangunan Gedung. Bandung

[3] Panitia Pembaharuan Peraturan Beton Bertulang Indonesia. 1971. Peraturan Beton Bertulang Indonesia. Bandung. Lembaga Penyelidikan Masalah Bangunan. xvi

[4] Wahyudi, Herman. 2013. Daya Dukung Pondasi Dalam. Surabaya. ITS Press

[5] The Overseas Coastal Area Development Institute of Japan (OCDI).2002. Technical Standards and Commentaries for Port and Harbour Facilities in Japan. Japan: Daikousha Printing Co.,Ltd.

[6] Thoresen, Carl A. 2003. Port Designer's Handbook. Thomas Telford. British.

[7] Velsink. 1994.Ports and Terminals Planning and Functional design 